\title{
Solutions to reduce moisture driven backout and improve withdrawal strength of nailplates - Experimental investigations
}

\author{
Alexander Mainey ${ }^{1} \bullet$ Benoit P. Gilbert $^{1} \bullet$ Henri Bailleres $^{2} \bullet$ Shanmuganathan Gunalan $^{1} \bullet$ \\ Matthew Smith ${ }^{3}$
}

Alexander Mainey alexander.mainey@griffithuni.edu.au, +61 449858 062, ORCID ID: 0000-0002-1417-7419

1 School of Engineering and Built Environment, Griffith University, Parklands Drive, Southport, Qld, Australia

2 Department of Agriculture and Fisheries, Queensland Government, 50 Evans Road, Salisbury, Qld, Australia

${ }^{3}$ Multinail Australia, Burnside Road, Yatala, Qld, Australia

\begin{abstract}
Timber trusses, typically manufactured from timber members connected by nailplates, are widely used in the domestic housing market. Their use is however limited to indoor environments. The exposure of timber trusses to environments where the timber experiences high amounts of moisture content (MC) variations causes the nailplates to be driven out from the surface of the timber, a phenomenon commonly referred to as "backout". As part as a collaborative project between the industry, Griffith University and Queensland Department of Agriculture and Fisheries (DAF), this paper aims at investigating solutions to both prevent backout of the nailplates and increase their withdrawal resistance under large MC variations. The nailplate teeth were redesigned following (i) a mechanical approach consisting
\end{abstract}


of redesigning the tooth profile and allowing the nails to resist the withdrawal force by both friction and mechanical action and (ii) the application of an adhesive to a redesigned tooth profile, allowing the adhesive to penetrate the timber with the nail. The efficiency of the new designs was experimentally assessed using single teeth (representative of nailplate teeth) with respect (i) to their ability to resist backout resulting from accelerated MC cycles and (ii) their quasi-static withdrawal resistance after increasing numbers of moisture cycles. Results showed that the proposed mechanical designs reduced the backout by up to $50 \%$ when compared to currently used tooth designs. The application of an adhesive prevented moisture driven backout. The newly investigated tooth designs resulted in higher withdrawal strengths to currently used nails. It was identified that subjecting the nails to only one moisture cycle reduced the withdrawal resistance of currently used and glued teeth by up to $60 \%$ while the withdrawal resistance of the proposed mechanical designs was not affected by the number of cycles.

Keywords Moisture driven backout, nailplate, withdrawal, adhesive

\section{Introduction}

Steel nailplated timber trusses are used in the vast majority of Australian residential houses, commonly forming the roof and flooring systems (Bylund 2017). Nailplates have been used for more than 50 years, with patents dated at least as far as 1962 (Atkins 1962). Over this time with the evolution of manufacturing machineries and an ever-increasing demand for prefabrication in the construction industry, steel nailplated timber trusses have become an essential component of the residential building market. They represent $28.5 \%$ of the $\$ 5.7$ billion Australian’s “Wooden Structural Component Industry” (Allday 2017). 
A 30 year old patent (Smith et al. 1988), shown in Figure 1, has generally been the design basis for nailplates currently used by Australia's manufacturers. This design aims at maximising the teeth number to plate area ratio by having two teeth cut per punched hole. The production rate of this design can be extremely high due to the metal stamping machineries available. This has been in conjunction with the pressing of the plate into the timber becoming a refined and efficient process due to the sharp teeth and off-site pressing technology.

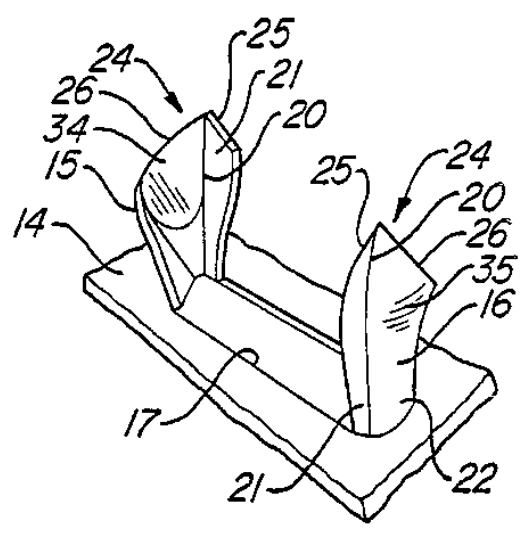

Figure 1: Nailplate tooth profile patent by Smith et al. (1988).

Currently, the use of nailplated timber trusses is limited to indoor environments where the system is protected from direct contact with water and large variations in temperature and humidity. Outside these circumstances, the nailplates would be "driven-out" from the timber as the timber shrinks and swells in response to its changing moisture content (MC). This withdrawal phenomenon is commonly referred to as "backout" (Paevere et al. 2009). Despite the economical nature of nailplated trusses in terms of both manufacturing and erection, the restriction of nailplated trusses being only viable in indoor environments results in a lost 
opportunity for the timber industry. A potential application for nailplated timber trusses in the open environment is for instance timber bridges.

To allow nailplated timber trusses to be used in external environments and have increased design strength, this paper investigates new nailplate tooth profiles which can prevent moisture driven backout and provide a greater joint strength through an increased nail withdrawal capacity. Two different design approaches are investigated herein and consist of redesigning the tooth profile to resist the backout forces (i) mechanically and (ii) with the chemical fastening of an adhesive which penetrates the timber with the teeth. The efficiency of the new designs, both in terms of backout rate and nail withdrawal capacity, is investigated and discussed at various numbers of accelerated MC cycles. Recommendations are made on the best design to use in a mass production industrial context.

Specifically, this paper presents first a literature review on nailplated joints and moisture driven backout. Secondly, the general principles and rationale behind the new tooth designs are argued. Thirdly, the testing methodology adopted to investigate the efficiency of the new designs is introduced. Finally, the backout rate, efficiency and nail withdrawal capacity at various MC cycles are presented and discussed.

\section{Literature review}

\section{Joint Characteristics}


Nailplated joints draw their strength from the friction interface between the steel teeth and the timber, with the array of teeth only being embedded $8-11 \mathrm{~mm}$ into the timber (the embedment length is often limited by buckling of the teeth as the plate is pressed into the timber). The performance of timber trusses is highly reliant upon the joint characteristics. These characteristics can include, but are not limited to, the timber orientation, the size of the nailplate and the position and type of load (tension or compression) (Wei Guo 2014). Depending upon the combination of these factors, different failure mechanisms are observed. They include yielding of the steel nailplate, plug-failure of the timber and nailplate withdrawal (Wei Guo 2014). The latter is the most common observed failure mode and may be better described as "plate peeling" for which a joint in tension will experience "arching" of the nailplate as the load increases (Melton 2000). The friction between the nail and the timber, generated by embedding the nailplate in the timber, is gradually lost as the plate peels away from the timber. An example of such a failure mode is shown in Figure 2.

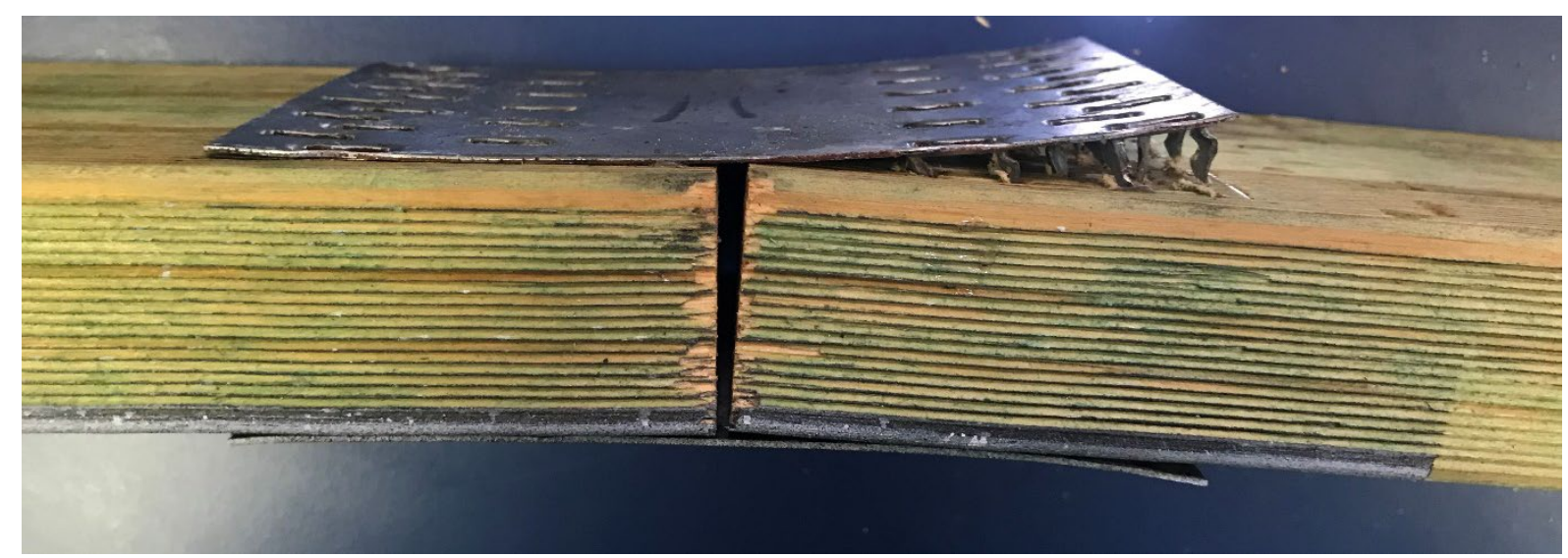

Figure 2: Nailplate withdrawal failure of a joint loading in tension with the plate "peeling" away from the timber 
Due to the proprietary nature of the nailplate industry, limited information is available regarding the actual performance of joints. Even the American Standard "National design standard for metal plate connected wood truss construction (ANSI/TPI 1-1995)" is based on proprietary testing from industry, which is unacceptable according to Melton (2000) and is only allowed by companies to gain competitive advantage. There is a lack of understanding of the fundamental principles which govern the behaviour of nailplates, which may have limited innovation. The currently used 30-year old nailplate design (Smith et al. 1988) being adequate for indoor use and light trusses, may not have also pushed innovation forward.

\section{Nailplate backout}

A study by the CSIRO (Commonwealth Scientific and Industrial Research Organisation) in Australia (Paevere et al. 2009) performed experimental tests on nailplated joints and demonstrated the influence of the nailplate backout on the joint capacity. It was found that a 1 mm backout (i.e. about $12 \%$ of the nail length in Paevere et al. (2008)) resulted in a $25 \%$ reduction in joint strength, while a $2 \mathrm{~mm}$ backout resulted in a $45 \%$ loss in strength, i.e. nearly half the capacity of the joint. Melton (2000) collected thirty-seven truss joint specimens where there was a visible backout of the nailplates from the parent timber. The author found that the backout, larger around highly stressed joints, caused the joint to have a capacity significantly lower than the one accepted by standards. As part of the study, Melton (2000) investigated the cause of the nailplate backout and while there was evidence that poor manufacturing and framing techniques could initiate backout, these defects were discarded as primary contributors to nailplate backout as only joints with higher in-service loading consistently had increased 
backout. Indeed, it is very unlikely that the highly loaded joints were the only joints with manufacturing defects.

McAlister (1990) observed nailplate backout after exposing a truss to direct weather for a one year period. Smulski (1993) observed that excessive heat and moisture caused the backout of the nailplates in floor trusses. Groom (1995) found that the backout is very dependent on the amplitude of the MC variation. Eight MC cycles of a nailplated joint between 9 and 15\% average $\mathrm{MC}$, only resulted in a $3-4 \%$ backout of the tooth length $(0.32 \mathrm{~mm})$. This is compared to $17 \%(1.32 \mathrm{~mm})$ of tooth length backout when the joints were cycled between 5 and $19 \%$ average MC over the same number of cycles. Groom (1995) describes the backout of the nailplates as being caused by the moisture hysteresis initiating dimensional changes in the lumber. Paevere et al. (2009) manufactured joints and exposed them to moisture cycles which led to observed moisture driven backout of the nailplates. The authors, similarly to Smulski (1993), described the backout as a ratcheting phenomenon of the nailplate relative to the timber surface due to the timber MC variations. Houška et al. (2000) found that the backout phenomenon is further enhanced by the loading on the joint. Examples of the nailplate backout are shown in Figure 3.
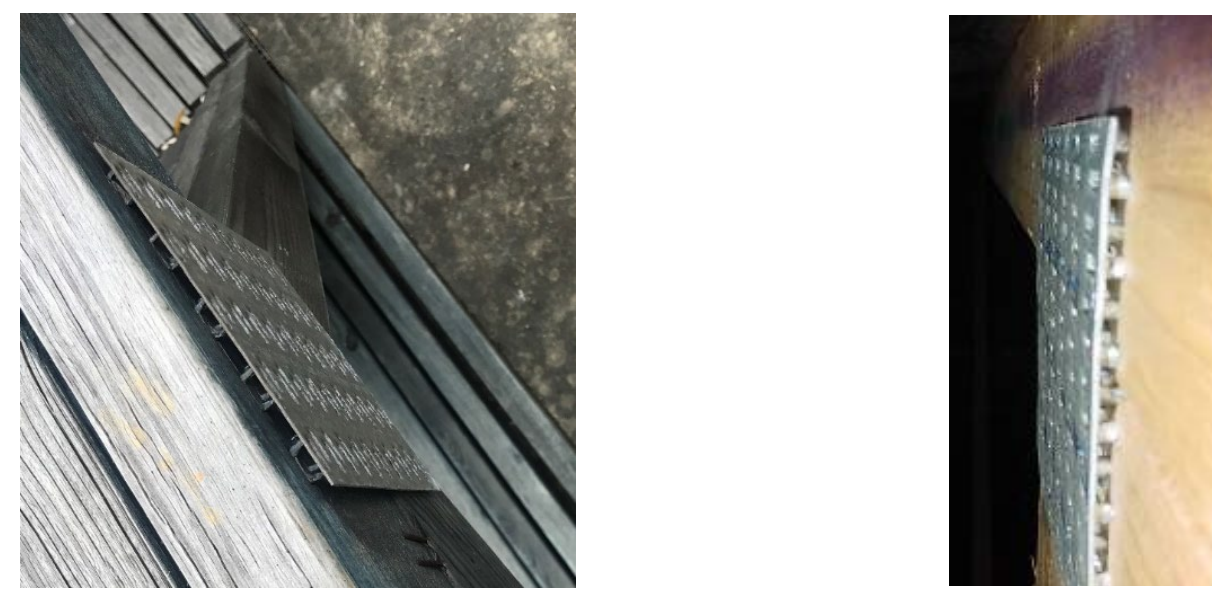
Figure 3: (a) Observed tooth backout of a nailplate from a truss left exposed on site prior to rain and sun. Location Gold Coast, Australia. and (b) backout observed within the roof space (Paevere et al. 2008)

While the backout is normally observed in environmental exposed conditions, it was also observed in Australia within certain roof spaces (Paevere et al. 2009). Paevere et al. (2009) found that the surface equivalent moisture content (SEMC) of the timber in roofs without a moisture barrier (sarking) varies between $2-18 \%$ in summer. In sarked roofs, it only varies between $5 \%$ and $11 \%$. In winter the SEMC varied between $7-22 \%$, and $10-22 \%$ in nonsarked and sarked roofs, respectively. This larger variation of moisture within the timber in non-sarked roofs would lead to larger shrinking and swelling of the timber, ultimately leading to backout of the nailplates of the roof trusses.

Melton (2000) reported that nailplate backout in the United States of America would cause sagging or springy floors and cracks in ceiling finishes. It is therefore important to reduce or stop the nailplate backout as not only is the joint capacity affected, the serviceability of the truss is also challenged.

A report by the Department of Agriculture and Fisheries (DAF) (Bylund 2017) identified that there is a need for nailplate manufacturers to keep up with the evolving market of prefabricated timber structures, particularly in Australian Class 2-9 buildings (i.e. buildings other than residential such as multilevel units or commercial buildings). To use nailplates in external 
environments, it was recommended that some new plate designs be proposed to meet the increased design demands.

\section{Published design innovations}

In the past, some researchers have investigated a variety of ways to increase the strength of nailplated joints and to prevent backout of the nailplates. Groom (1994) investigated the influence of coating the nailplate teeth with an epoxy resin on the backout rate and overall joint's mechanical properties. Results showed that the epoxy coating had no influence on the backout rate after eight mild cycles, consisting of a $\mathrm{MC}$ ranging between 9 and $15 \%$. However, it proved effective in reducing the nailplate backout by approximately $25 \%$ after eight severe moisture cycles, i.e. with a MC ranging between 5 and 19\%. The application of the epoxy also increased the strength and stiffness of the nailplated joint by up to $9 \%$ and $28 \%$, respectively. While the increase in strength remained throughout all investigated moisture cycles, the increase in stiffness was rapidly lost. The epoxy glued and the non-glued control joints lost $67.2 \%$ and $49.8 \%$ of their initial stiffness after one severe moisture cycle, respectively. Some level of deterioration of the adhesive interface between the nail and the timber has therefore likely occurred after the first severe moisture cycle.

To study the best design for nailplates pressed into the end grain of railway sleepers, Regan et al. (2002) investigated the withdrawal strength of nailplates pressed into red oak wood. Several testing regimes were suggested and the withdrawal strengths of two different nailplate designs were quantified. The two designs differed only in the layout of the nails. It was found that the 
plates with a staggered tooth pattern and increased number of rows of teeth have a higher withdrawal strength.

Paevere et al. (2009) conducted a series of shrink-swell tests to investigate the effectiveness of sealants (similar to a plastic cover over the nailplate) being placed along the length and on top of nailplated joints in reducing the nailplate backout. Various parameters, such as timber species and sawing orientation (back-sawn and quarter sawn), were also explored. The samples were wet (using a spray bottle) and dried (at room conditions) 800 times over a 3-year period. It was found that the 'Seal n Peel' 660 sealant did not stop the backout of the nailplate due to the seal breaking and likely allowing more moisture to enter the joint area, while the 'Seal $n$ Peel' WB500 sealant proved effective. No comment was made regarding why WB500 stopped backout but was likely due to the sealant preventing moisture entering the timber completely (the joint was simply wet using a "spray-bottle"). It was also noted that the timber species and sawing orientation had no discernible influence on the nailplate backing out. The average nailplate withdrawal (under no load and no sealant) was $0.40 \mathrm{~mm}$ and $3.02 \mathrm{~mm}$ after 100 and 800 cycles, respectively. With respect to the sealant, concerns were expressed over the associated increased manufacturing and material costs.

\section{Material and methods}

\section{General}

This section first presents the principles behind the investigated new nailplate teeth aiming at increasing the tooth withdrawal resistance. Based on industry requirements, the following limitations were imposed on the concepts: 
1. Two teeth need to be punched per hole, as shown in Figure 1, to maximise the number of teeth over the plate surface area ratio;

2. The nails need to be able to be punched with minimum change to existing manufacturing tools and at the current production rate;

3. The steel plate material needs to remain the same as the one currently used.

Secondly, the proposed methodologies to assess (i) the ability of each design to reduce moisture induced backout and (ii) the withdrawal capacity of each design after various MC cycles are presented. Note that this study investigates the efficiency of the new designs using only single teeth based on the observations in Foschi (1977). Foschi (1977) modelled nailplate joint behaviour based on the properties of a single tooth with excellent agreement with experimental results. The effect of the parent plate buckling and its contribution to joint stiffness is accounted for with one coefficient while the non-uniform loading of a tooth in a nailplate array can be accounted for with another coefficient for each tooth. However, the high density of teeth within a nailplate means that the coefficient for load distribution between each tooth will have a mean value of 1.0. Based on these findings it is deemed acceptable that just using a single tooth will provide a reliable baseline of how new tooth profiles may affect nailplated joints. The use of a single tooth will be far more economical when trying to investigate of a variety of tooth designs but more importantly it will enable the mechanisms causing the backout of nailplated joints to be better isolated.

\section{Investigated concepts}




\section{Mechanical approach}

As mentioned earlier, commonly used teeth design's withdrawal resistance is solely based on the friction force developing between the teeth and the timber. As the nailplate withdraws from the timber, the friction surface is reduced, therefore reducing the friction force and eventually leading to a reduced joint capacity. To compensate the loss of frictional force during withdrawal, hooks are proposed to be shaped within the tooth profile. The hooks are designed to grab the timber fibres as the tooth withdraws, either due to moisture driven backout or as the plate peels off when testing the joint in tension (Figure 2). The idea is to facilitate the grabbing of the timber by the nails, the hooks can either fold when entering the timber and unfolding during withdraw or take an alternative path to the entry one on exit.

Initially, four mechanical design principles were investigated with 3 to 5 variations (dimensions and angle of hooks) for each design, totalling 18 different designs. Based on preliminary testing where the nails were pressed into the timber and withdrawn, only the best two designs were further analysed and are presented in this paper. These two designs are referred herein as Mechanical Design 1 (MD1) and Mechanical Design 2 (MD2). MD1 consists of a hook bent at the tip of the nail where the hook will bend almost $180^{\circ}$ as the nail enters the timber. While MD2 consists of a hook bent on the side of the nail and away from its tip. Figure 4 shows a model of MD1 and MD2 and Figure 5 gives associated photos.

\section{Adhesive approach}

The adhesive approach focuses on maximising the effectiveness of the adhesive by providing mechanisms to allow the glue to penetrate the timber with the tooth. The tooth is shaped with a groove (or small hole) in the tooth profile so the glue is embedded in the tooth and not just 
coated on top to prevent the sweeping of the glue when inserted into the timber. In Groom (1994), discussed previously, the glue was likely forced to the base of the nail (connection with the plate) during the nailplate penetration, limiting its efficiency as no or little glue penetrated the wood. Moreover, the high degradation rate after moisture cycling of the enhanced mechanical properties obtained from the glue application in Groom (1994) also likely resulted from the high stiffness and brittle nature of the epoxy resin used. It is plausible that a more ductile adhesive would increase the effectiveness of the glued nails after MC cycling and polyurethane base structural adhesive is therefore proposed for use in this study.

In the initial stages of this study, similar to the mechanical design approach, preliminary testing of the effectiveness of the glue designs was performed. A tooth with a means to allow the glue to penetrate the timber was compared to that of just a simple tooth with glue only applied to the tooth. The tooth without the ability to have the glue penetrating the timber was only able to reduce moisture induced backout by $50 \%$ compared to a no-glue tooth, while the added design feature, allowing the glue to penetrate the timber, completely stopped the moisture induced backout (Mainey et al. 2016).

One design layout (the tooth with the added feature) is investigated herein and is referred to as "Glue". 


\section{Testing Methodology}

\section{Timber samples and nails}

Sixty-three timber samples of dimensions $90 \mathrm{~mm}(\mathrm{~L}) \times 70 \mathrm{~mm}(\mathrm{~W}) \times 35 \mathrm{~mm}(\mathrm{H})$ were cut from 2.4 m long MPG10 (Standards Australia 2006) graded Radiata Pine (Pinus radiata) boards, as shown in Figure 6 (a) and Figure 7. Samples containing knots and resign pockets were avoided as much as possible. In each sample, four nails consisting of one of each analysed design (MD1, MD2 and Glue) and one "Base" nail, representing the currently used and unmodified nail, were pressed $11 \mathrm{~mm}$ deep using a $30 \mathrm{kN}$ Universal Instron Testing Machine at a stroke rate of 11 $\mathrm{mm} / \mathrm{min}$. The nail positioning is given in Figure 6 (a) (indexed by A, B, C and D in the figure) and is in accordance with the minimum allowable distance between nails in the Australian Standard AS1649 (Standards Australia 2001). To remove the effect from the nails being pressed into the same growth rings within the same MGP10 board, the four designs were always pressed in the order Base, MD1, MD2 and Glue, but with the Base design starting at either location index A, B or C, depending on the piece group as discussed later.

From each $2.4 \mathrm{~m}$ long board and in an attempt to keep consistency in the results between MC cycles, boards were cut in groups of seven pieces to match the seven cycle increments discussed later in this section. The pieces in a group are adjacent to one another in the board. The first piece in a group was used for the first cycle increment, the second for the second increment up to the seventh for the last increment. Figure 5 demonstrates the cutting and labelling system for one $2.4 \mathrm{~m}$ long board where each piece was identified by its cycle increment that it was to be subjected to and its group number. 
The nails were laser cut (with $+/-0.1 \mathrm{~mm}$ accuracy) from the same type of galvanised steel sheet (nominal thickness of $0.95 \mathrm{~mm}$ ) that is currently used to manufacture nailplates by one Australian manufacturer. Note that while laser cutting influences the mechanical properties of the steel, its influence is only limited to the location of the cut (O'Neill et al. 2000), and the properties of the overall plate itself are unaffected. Moreover, as the withdrawal mechanism is principally a friction phenomenon (Paevere et al. 2009), how the steel was cut and its localised mechanical properties at the cut will not influence the backout mechanism. To facilitate the experimental work, the nails were $4.5 \mathrm{~mm}$ wide, i.e. $35 \%$ wider than existing nailplate nails. The width of the nail was increased to allow for the hook to be manually manipulated (using hand tools). A smaller size would have made it impossible to fold the hooks to the desired shape using hand tools. Should the design prove effective, an automated and more exact process for folding the hooks in the tooth is possible. It was deemed that increasing the tooth size for this study would not affect the mechanisms behind the withdrawal resistance and backout rate based on the work in Gebremedhin et al. (1991). These authors found that the moment of inertia and the width of the teeth do not influence the overall joint strength. The nail dimensions are shown in Figure 6 (b) and a picture of the base nail is shown in Figure 6 (c).

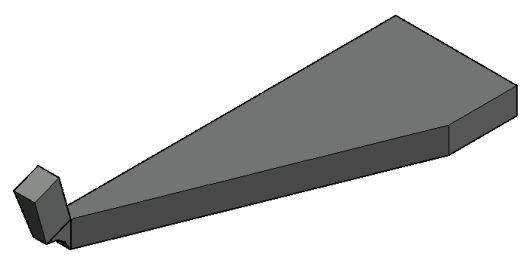

(a)

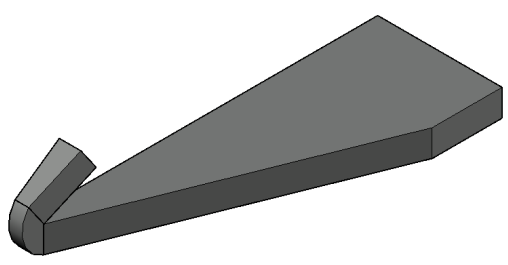

(b)

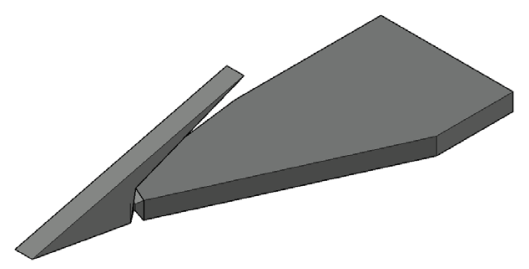

(c)

Figure 4 Representative and simplified models of: (a) MD1 (pre-bent), (b) MD1 (after hook is bent) and (c) MD2 


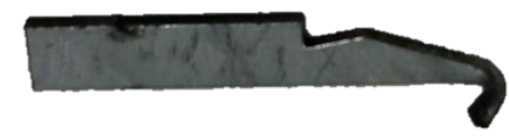

(a)

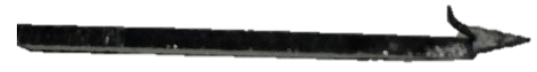

(b)

Figure 5 Photos of (a) MD1 and (b) MD2

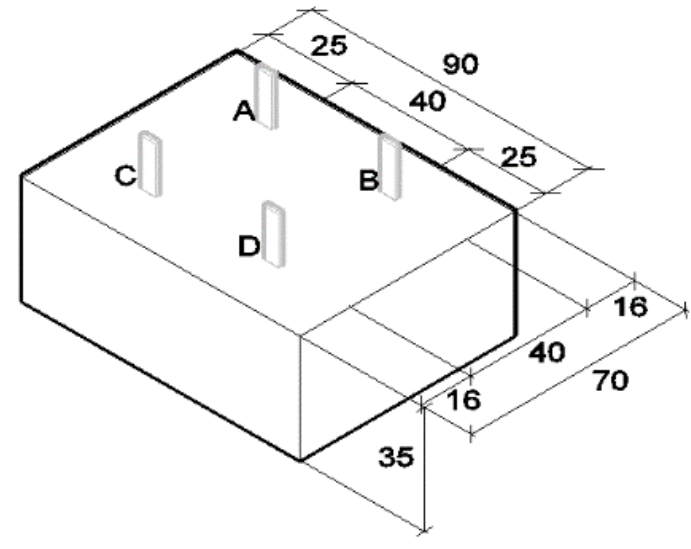

(a)

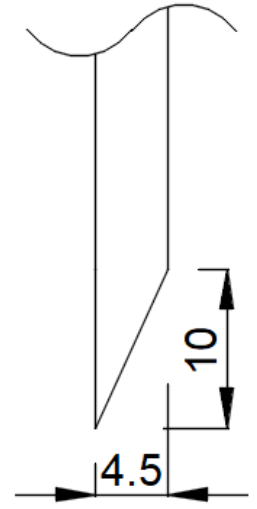

(b)

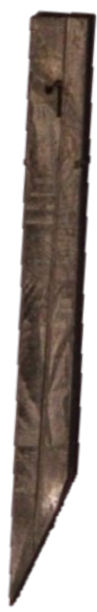

(c)

Figure 6 (a) Nail layout on sample, (b) Nail dimensions, (c) Picture of base nail 


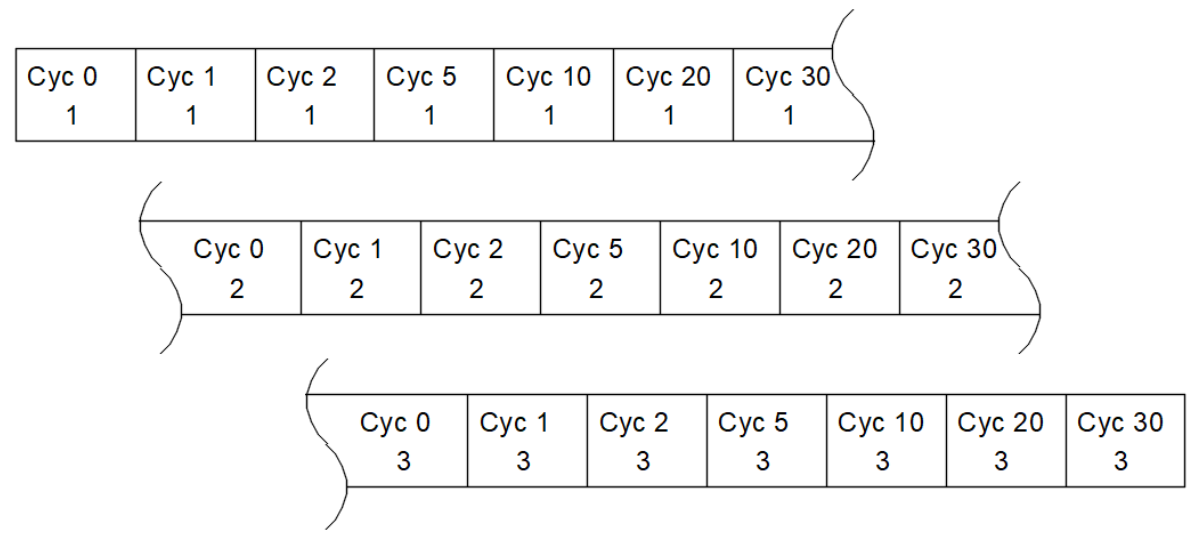

Figure 7 Cutting plan for one $2.4 \mathrm{~m}$ long MGP10 board.

\section{Moisture cycling}

To induce backout of the nails, the timber samples were subjected to a schedule of extreme and accelerated wetting and drying cycles. The samples were on average steamed for 2 hours and dried for 19 hours. One MC cycle is defined as the complete wetting and complete drying of a specimen. The cycles aimed at targeting high $\mathrm{MC}$ variation in the timber following (i) the microclimate recordings made by Paevere et al. (2009), with SEMC which could vary between $2 \%$ and $22 \%$ annually and (ii) the experimental studies by Groom (1995) that induced a 1.35 mm nailplate backout in 8 cycles with a MC variation between 5\% and $19 \%$. For the wetting phase, the steam was applied into a plastic container using a steaming unit with the samples evenly spaced out inside the container. For the drying phase, the samples were dried overnight (or over the weekend) in a dehydrating oven at $40^{\circ} \mathrm{C}$.

Note that different wetting and drying techniques were initially investigated to backout the nails with mixed results. Methods tested to wet the timber also included (i) the use of an autoclave (at $136^{\circ} \mathrm{C}$ and $195 \mathrm{kPa}$ ), (ii) soaking the pieces in either room temperature water or 
warmed water $\left(60^{\circ} \mathrm{C}\right)$ and (iii) vacuuming the air in the timber pieces and replacing it with water. Methods to dry the timber also included using an air-driven kiln. Due to resource availability and effectiveness, the use of hot steam and a dehydrating oven was preferred. This technique was found to drive the nails out more effectively than the other investigated ones and is likely closer to reality where the timber is absorbing water in the form of vapour and not liquid form.

\section{Withdrawal force measurements}

Withdrawal of the nails was undertaken at seven different moisture cycles increments, corresponding to no wetting or drying, $1^{\text {st }}, 2^{\text {nd }}, 5^{\text {th }}, 10^{\text {th }}, 20^{\text {th }}$ and $30^{\text {th }}$ cycles. After each cycle increment, nine timber samples were removed from the cycling regime and put aside to measure the nail withdrawal force. These samples were placed in a climate chamber at $20^{\circ} \mathrm{C}$ and $65 \%$ relative humidity $(\mathrm{rH})$ to target an equilibrium $\mathrm{MC}$ of $12 \%$. An additional 14-day relaxation period, after the time the samples reached equilibrium, was also observed for each sample.

The withdrawal tests were undertaken following the guidelines for single nail withdrawal in the Australian standard AS1649 (Standards Australia 2001). Each tooth was withdrawn using a $30 \mathrm{kN}$ capacity universal Instron testing machine. The set-up is shown in Figure 8 (a) and a photo of the nail holding device and timber is shown in Figure 8 (b). The samples were clamped to a rigid frame and the nails were clamped to the machine loading head. The teeth were then pulled-out in displacement control at a stroke rate of $2.5 \mathrm{~mm} / \mathrm{min}$. The vertical displacement $(\Delta)$ of the nails was measured as the average recording of two Linear Variable Displacement Transducers (LVDTs), symmetrically attached to the loading head and measuring the relative 
displacement between the head and the rigid frame. Note, as the load cell is used at up to $1 \%$ of its capacity (see pull-out force values in Results and Discussion), its accuracy for the encountered load range was verified before testing using calibrated masses. The load cell readings were found to be within $3 \%$ of the known applied loads.

The work (W) required to pull-out one tooth is calculated as:

$$
\mathrm{W}=\int_{0}^{z} F(\Delta) d \Delta
$$

Where $F$ is the resisting force of the tooth after it has been withdrawn by a distance $\Delta$ from the timber surface and $\mathrm{z}$ is the depth of the tooth in the timber.

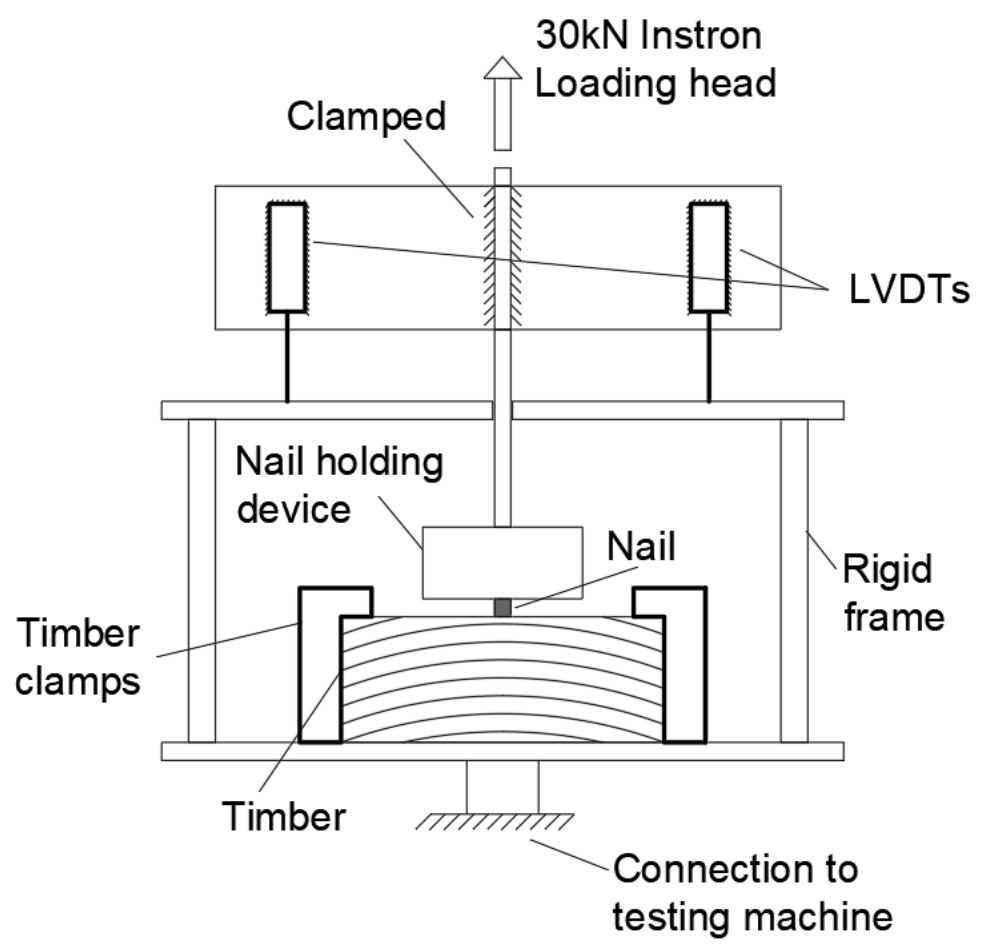

(a) 


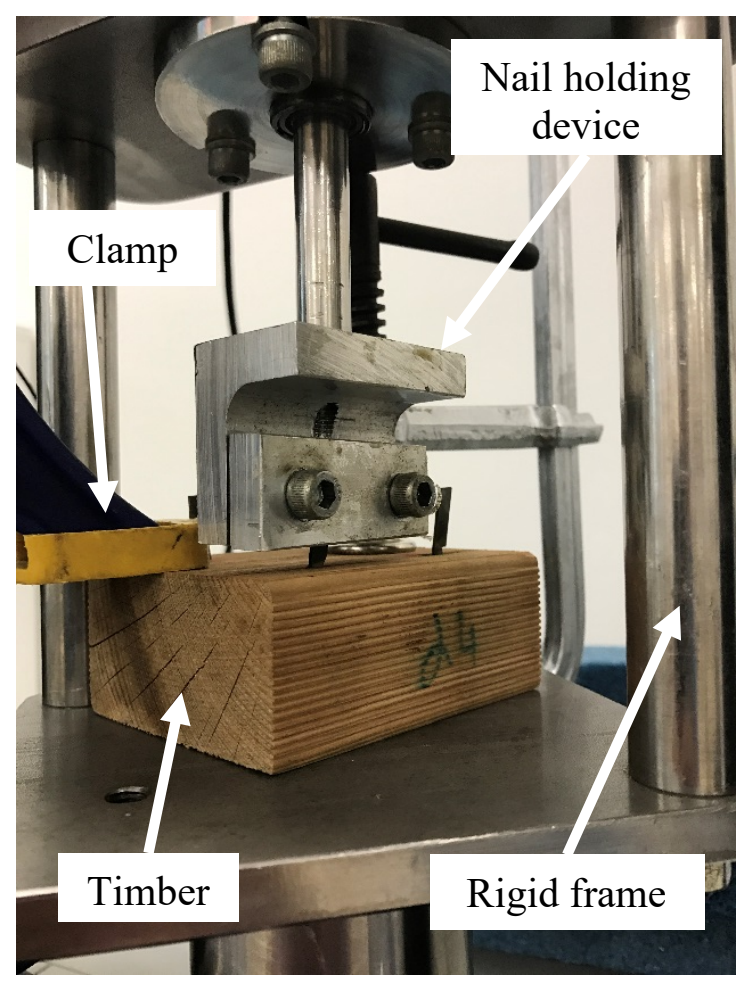

(b)

Figure 8 Nail withdrawal test set-up, (a) schematic and (b) photo

\section{Backout and MC measurements}

The height of each tooth relative to the timber surface was measured after each MC cycle (drying phase) using a digital veneer calliper. At the end of each wetting and drying cycle, the samples were weighed and their MC at this point of time was determined at the end of the overall test program using the oven dry method, as specified in the Australian and New Zealand standard AS/NZS 1080.1 (Standards Australia 2012). 
Note that since nine samples were removed at each cycle increment to measure the nail withdrawal force, the average backout calculated at each drying cycle was based off a decreasing number of samples for each increment, as seen in Table 1.

Table 1 Number of tests for which the nail backout was measured

\begin{tabular}{lc}
\hline Cycle number & $\begin{array}{c}\text { No. of test pieces monitored after } \\
\text { each cycle }\end{array}$ \\
\hline $\mathbf{0 - 1}$ & 54 \\
$\mathbf{1 - 2}$ & 45 \\
$\mathbf{2 - 5}$ & 36 \\
$\mathbf{5 - 1 0}$ & 27 \\
$\mathbf{1 0 - 2 0}$ & 18 \\
$\mathbf{2 0 - 3 0}$ & 9 \\
\hline
\end{tabular}




\section{Results and discussion}

\section{Backout rate}

The average backout of each nail design after each drying cycle is shown in Figure 9, along with the measured wet and dry MCs of the timber samples. The distribution of the recorded backout measurements is given with box plots in Figure 10 for clarity.

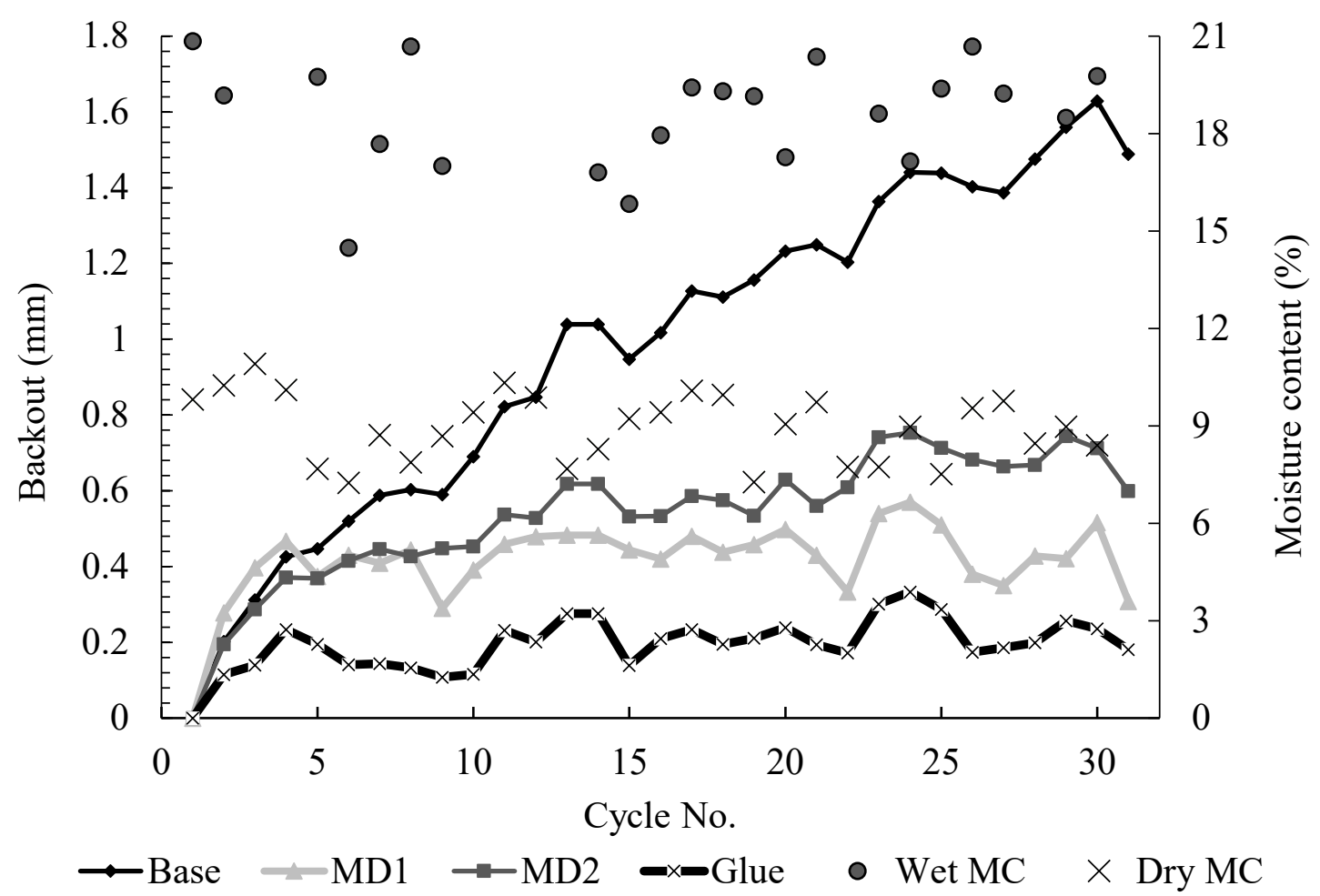

Figure 9 Average backout measurements of the nails with the average wet and dry MCs of the timber samples 


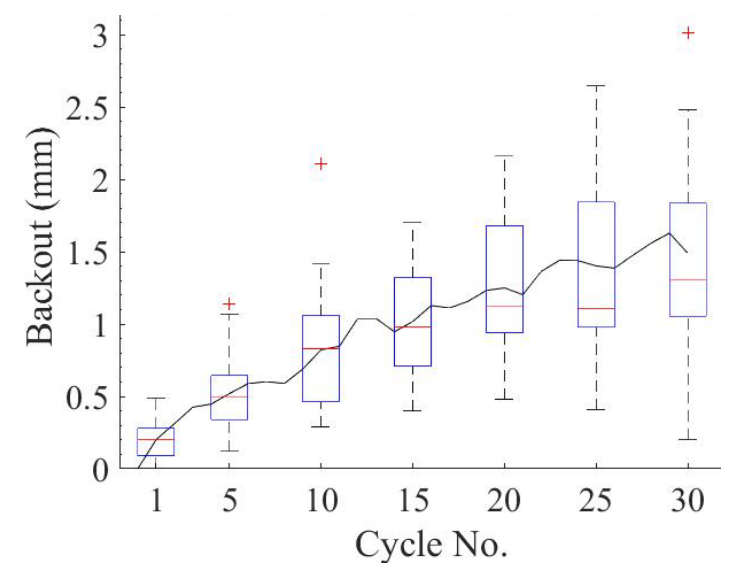

(a) Base design

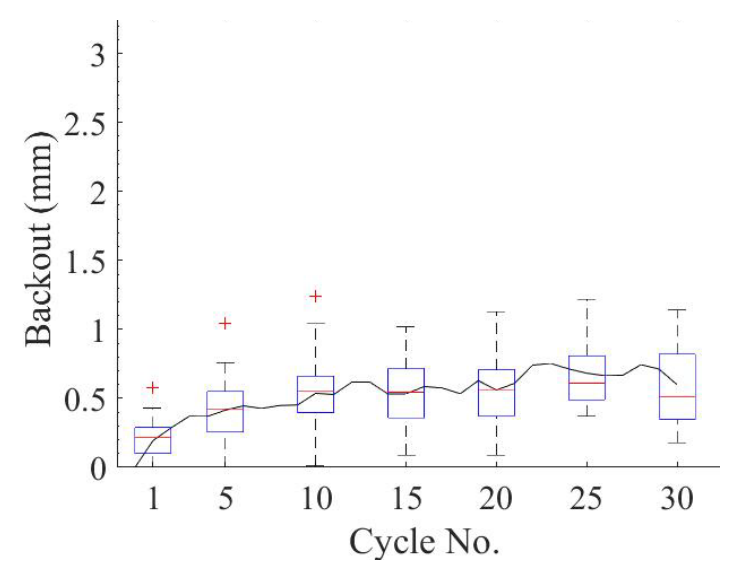

(c) MD2

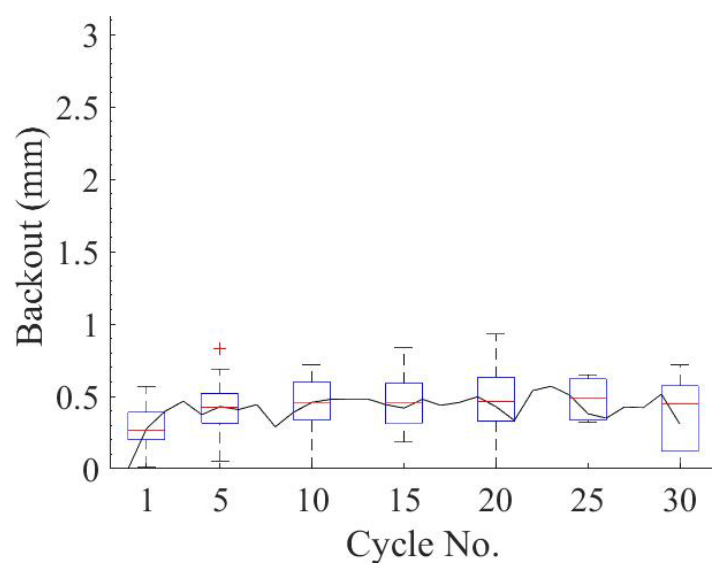

(b) MD1

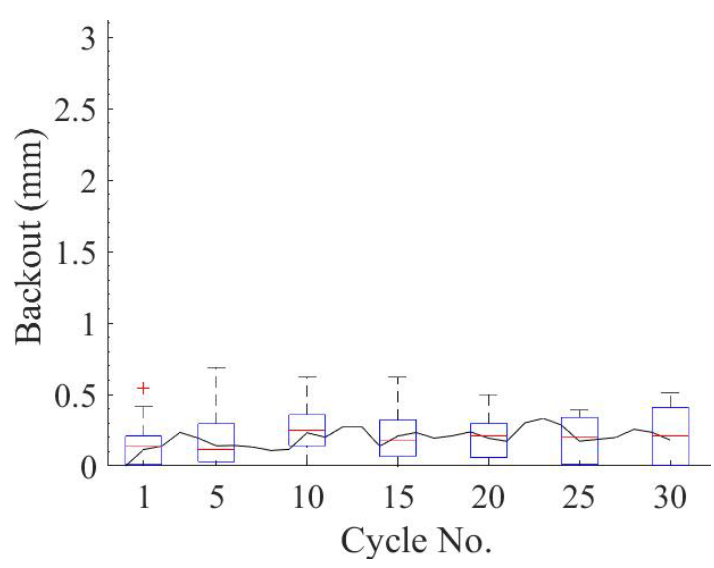

(d) Glue

Figure 10 Box plots showing the distribution of nail backout measurements. The solid line represents the average measured backout value

After 30 cycles, the backout of the commonly used base design was on average $1.6 \mathrm{~mm}$. In contrast the MD1, MD2 and glue designs only backed out by $0.7,0.5$ and $0.2 \mathrm{~mm}$, respectively. For comparison and as mentioned earlier, Groom (1994) who investigated the backout rate and joint strength deterioration of full nailplates, recorded approximately $1.35 \mathrm{~mm}$ of backout after 8 severe (5-19\% MC) cycles. It is worth noting however that the cycle length in Groom (1994) averaged approximately 27.5 days compared to the 24 hour cycles induced in this study. This 
difference would likely lead to different MC gradient in the timber and different ratcheting backout amplitudes.

Figure 9 shows that for the initial 3 to 5 cycles, the mechanical designs backed-out at the same rate as the base design (about $0.1 \mathrm{~mm}$ per cycle). However, after a backout of about $0.4 \mathrm{~mm}$, the hooks incorporated into the designs likely grabbed timber fibres and significantly slowed down the backout rate. Backout almost completely stopped after 5 cycles for MD2. The effectiveness of the mechanical designs is also reflected in the box plots (Figure 10) where the variations in the observed backout values are significantly smaller $\left(50^{\text {th }}\right.$ percentile range of 0.5 $\mathrm{mm}$ for MD1 and MD2 at 30 cycles $)$ than of the ones of the base design $\left(0.8 \mathrm{~mm} 50^{\text {th }}\right.$ percentile range at 30 cycles). With the integration of a mechanical hook in the tooth design, the mechanisms resisting withdrawal have likely changed from pure friction in the base design to a combination of friction and "grabbing" or "hooking" of the timber. However, these actual mechanisms still need to be further analysed outside the scope of this study.

The glue design also demonstrates how the transition from a pure friction design to a design based on friction and adhesion can greatly reduce the backout rate. After the first 3 or 4 cycles, in which the glue design has backed out relative to the timber surface by $0.2 \mathrm{~mm}$, the glued teeth did not backout any further from the timber surface. The effect of the glue on the backout rate was almost universal across all 54 samples that were subjected to varying MCs. This is reflected in Figure 10 (d) where a low variance in the backout amounts can be observed relative to the base design (i.e. the variance of the base and glue designs across all cycles is 0.42 and 0.044 respectively). A comment can also be made with respect to the difference between the mean (solid line) and the median (horizontal line in the boxplot box) shown in Figure 10. As the number of cycles increased, the difference between the mean and the medial started to 
increase for the base design and to some extent, MD1, however the MD2 and glue designs had almost matching median and mean readings throughout the 30 cycles.

It is noted that after about 23 cycles, about $25 \%$ the base design nails had become "loose" and would "wobble" when trying to measure the backout. This however did not occur for the other investigated designs and this effect is reflected in the withdrawal strengths of each of the designs, as detailed in the following section.

\section{Withdrawal strength}

Figure 11 demonstrates that the maximum force required to withdraw the base design deteriorated by more than $60 \%$ (from $127 \mathrm{~N}$ to $49 \mathrm{~N}$ ) after just one moisture cycle. A drop of $52 \%$ (from $301 \mathrm{~N}$ to $158 \mathrm{~N}$ ) after just one moisture cycle is also observed for the glue design, with the average maximum withdrawal force dropping to a similar force as the mechanical designs. This immediate reduction in withdrawal strength likely results from a bond damage between the glue and the timber. While the polyurethane glue used is relatively flexible compared to alternate options such as an epoxy, the timber, and subsequently the timber around the tooth would have experienced substantial deformation due to the shrink-swell nature of timber. Interestingly, the deterioration of the withdrawal capacity after one MC cycle contrasts with the efficiency of the design in preventing backout of the nail (see Figure 9). This drop off in strength is also reflected in the findings in Groom (1994) where the stiffness of a nailplate joint with adhesive decreased by $67.2 \%$ after just one severe moisture cycle. However, with either the difference in the type of adhesive used, the proposed tooth profile allowing the glue to penetrate the timber or both, this investigated design demonstrates that adhesive based 
designs can practically stop moisture driven backout while ensuring withdrawal capacities are $236 \%$ and $253 \%$ higher that of the base design after 0 and $30 \mathrm{MC}$, respectively.

Contrary to the base and glue designs, the mechanical designs did not experience the same deterioration in withdrawal resistance. The maximum average withdrawal forces are $110 \mathrm{~N}$ for MD1 and $127 \mathrm{~N}$ for MD2 after zero cycle. They marginally increase after one moisture cycle to $145.4 \mathrm{~N}$ and $132.9 \mathrm{~N}$ for MD1 and MD2, respectively, to remain at about the values for all remaining $\mathrm{MC}$ cycles. The use of the anchor in the mechanical design also substantially increases the consistency in the withdrawal force, with a Coefficient of Variation (COV) at the $30^{\text {th }}$ cycle of 0.28 for both MD1 and MD2, compared to 0.38 for the base design. In comparison to the base design, MD1 and MD2 has a $355 \%$ and $312 \%$ higher withdrawal resistance after 30 MC, respectively.

The average work required to withdraw each tooth design at each cycle increment is shown in Figure 12. The work to remove each nail was calculated using Eq 1 was made to quantify the shapes of the withdrawal curves shown in Figure 13. The noticeable jump in MD1 and MD2 after one MC indicates that the timber shrinking and swelling around the nail must have engaged the anchor/hooks in the design.

Figure 13 plots representative tooth load-displacement curves for each design after $0,1,2,5$, 10 and 30 cycles for six almost adjacent timber pieces. All curves show an initial high stiffness. Contrary to the base and glue designs, the mechanical designs show a high non-linear response before reaching a plateau. After at least one cycle and after reaching the maximum force for the base and glue designs, the load decreases almost linearly with the withdrawal displacement. However, these two designs at Cycle 0 have a different behaviour than the one of the other 
cycles, with the load dropping suddenly after reaching the peak load, although it is not as pronounced for the base design as for the glue design. This effect was observed across most of the other eight samples, indicating that one extreme moisture cycle is enough to induce some damage of the adhesive interface between the tooth and the timber. Figure 13 also shows that MD2 tends to have a sharp drop off in the load, usually just after reaching the peak load. This typically coincided with a loud cracking noise. After completely removing the tooth from the timber, it was observed that the cracking noise was either the hook breaking off the nail or breaking of the timber fibres. Figure $14(a, b)$ shows withdrawn teeth photos of the mechanical designs demonstrating that the anchors have grabbed timber fibres on their way out. Visual inspection of the tooth hole and tooth itself after withdrawal showed how the base design and glue design left clean holes (Figure 14 (c, d)), while MD1 and MD2 caused substantial damage around the hole after being withdrawn. While the glue design tooth did not cause observable surface damage, timber fibres were visible on the nail surface (a cohesive failure of the glue and timber interface).

The variation of the average maximum withdrawal force and the average work required to completely remove each tooth from the timber samples are shown in Figure 11 and Figure 12, respectively, against the number of MC cycles. For clarity and to show the variation in the measurements, Figure 15 shows the box plots of the withdrawal force for each design on individual graphs. The box plots show a reduced variation in the maximum withdrawal strengths with increased cycles for the glue design, possibly indicating a stabilisation of the failure modes. From observations of the modes of withdrawal failure and understanding of the mechanisms resisting nail withdrawal, the maximum withdrawal strength of the glue teeth is a mix of friction between; i) the nail and timber, ii) hooking of solid glue onto timber fibres and iii) adhesion between the glue, tooth and timber. This mix would be hard to predict after only 
a few MCs; however, as the nails and the timber experienced increased numbers of MCs, the glue interface between the timber and the steel tooth deteriorate to a point that where the failure mode is a more consistent mix of friction, hooking and adhesion.

\section{Preferred option}

When comparing the glue to the mechanical designs, the main difference in performance lies in the glued design having a reduced moisture driven backout and a more reliable withdrawal strength (as indicated in Figure 9 and Figure 15 respectively). However, to manufacture the nailplates with glue, a substantial increase in costs will occur, not only with the raw glue, its application, but also potentially in increased quality control requirements and maintenance of machinery. In contrast, the implementation of the hook/anchor into the plate would only require a modification to the die from which the plates are punched. While the dies to manufacture nailplates (and a design similar to MD1 or MD2) are often expensive (in excess of $\$ 50,000$ AUD), if the mechanical designs can produce similar performance for outdoor environments to the glue design, it has the potential to be more accepted by industry. Overall the difference between MD1 and MD2 is negligible and the choice on the design would be based on the ease through which the hook/anchor can be implemented into the manufacturing process. 


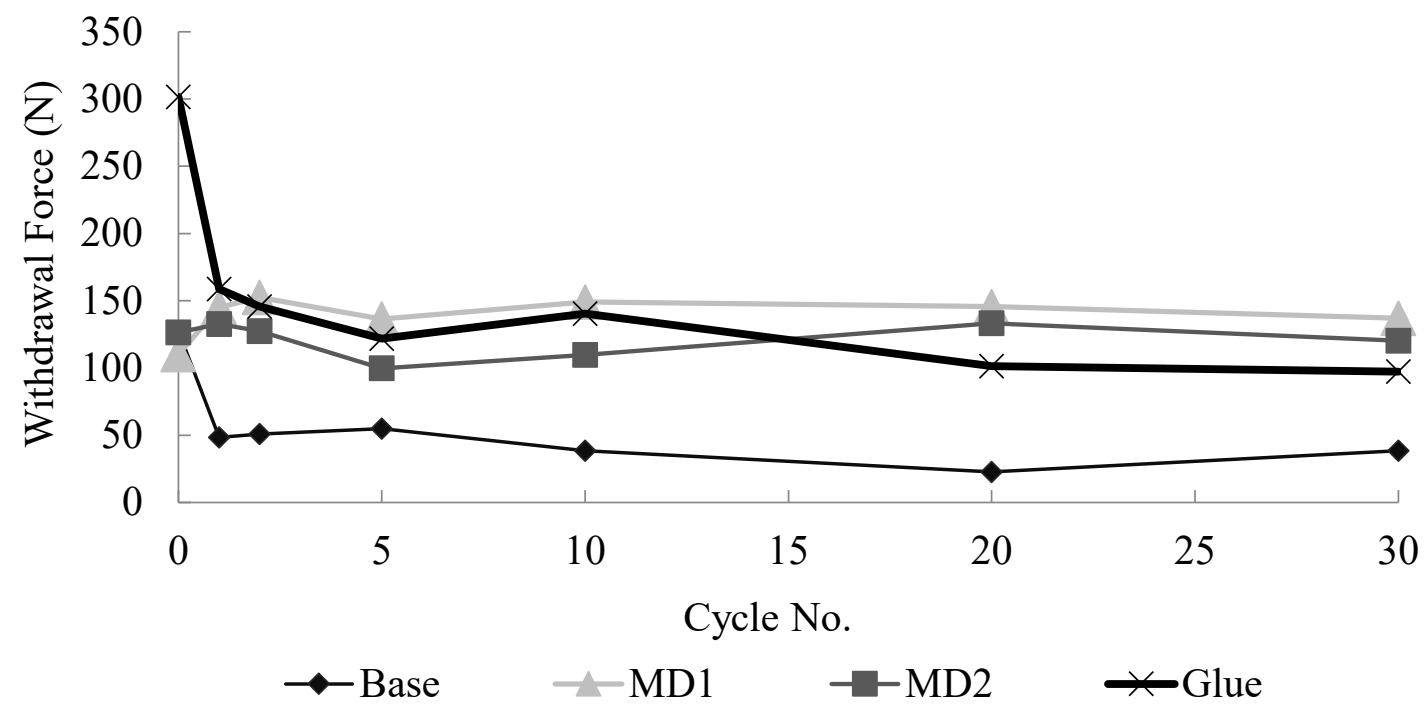

Figure 11 Average measured withdrawal force for each nail design versus number of MC cycles

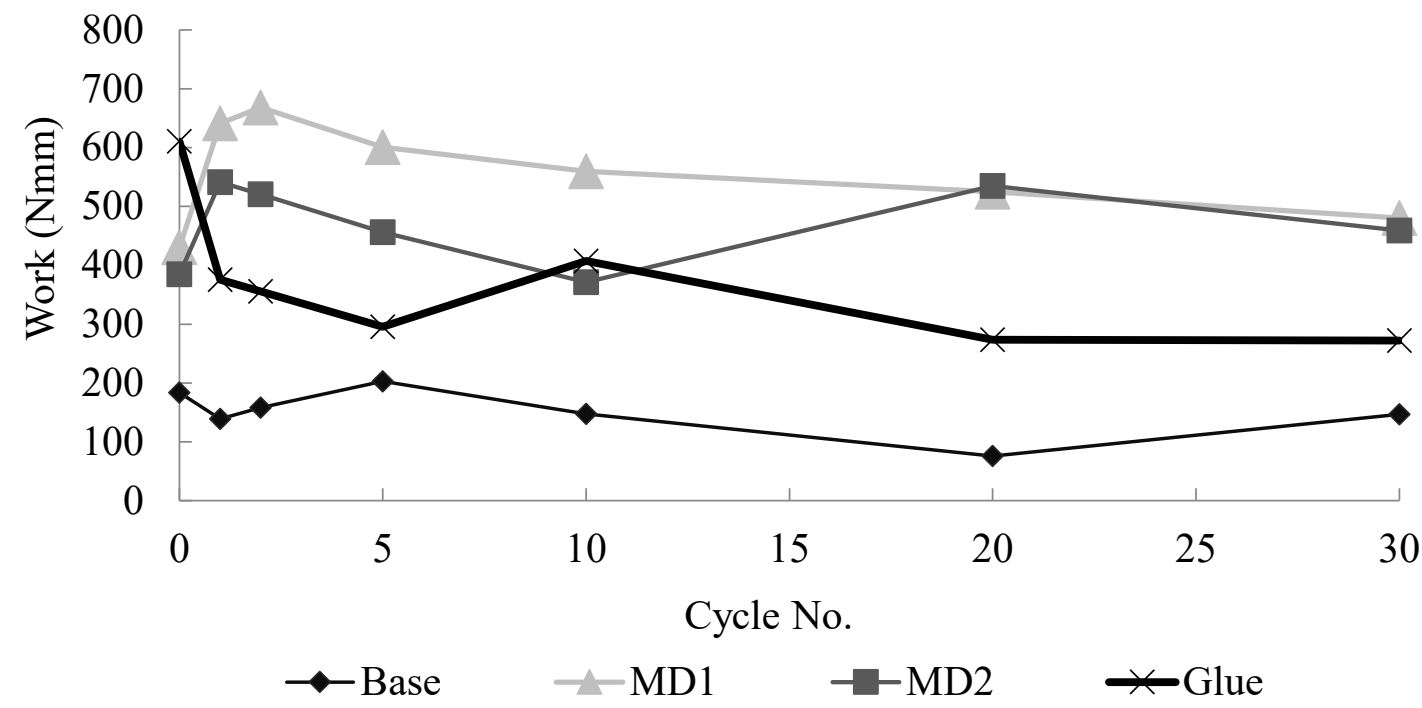

Figure 12 Average work required to withdraw each nail design versus number of MC cycles 


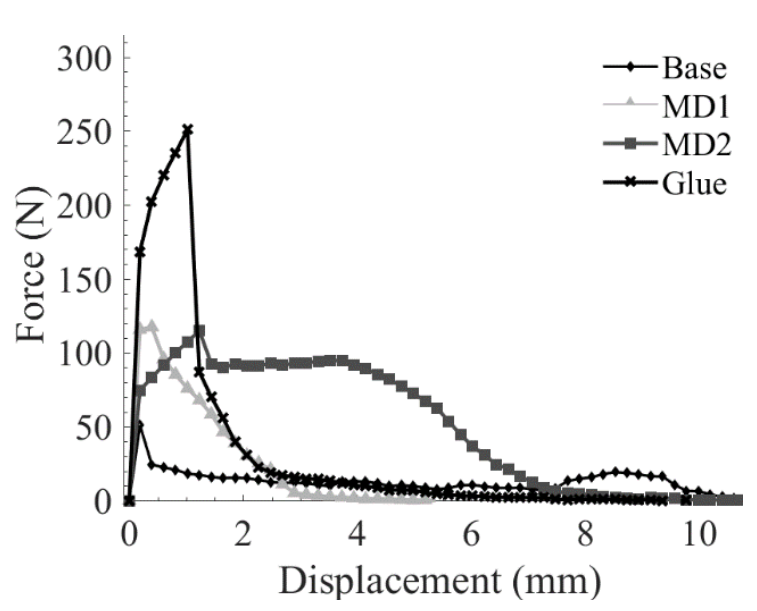

(a)



(b)

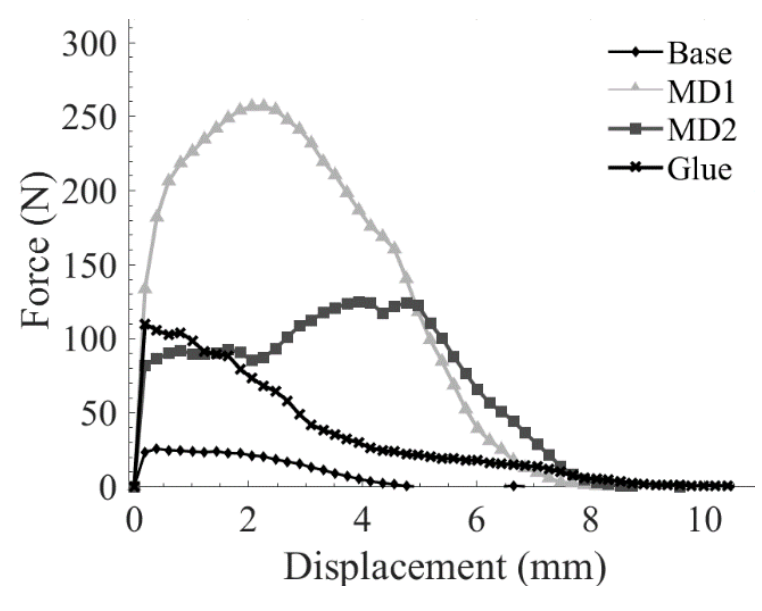

(d)

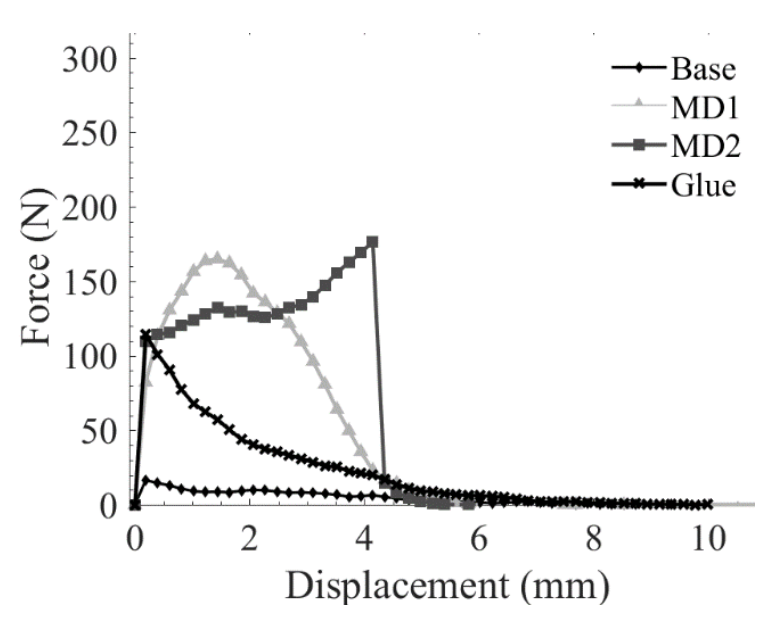

(e) 


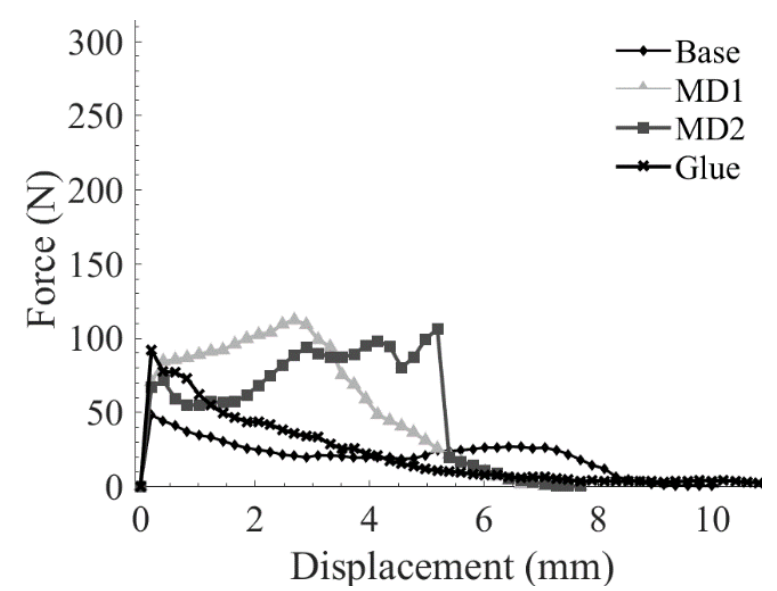

(c)



(f)

Figure 13 Representative withdrawal curves for nails from batch 5 after 0, 1, 2, 5, 10 and 30 cycles (indexed a, b, c, d, e, and f respectively).



(a) Base



(b) MD1 


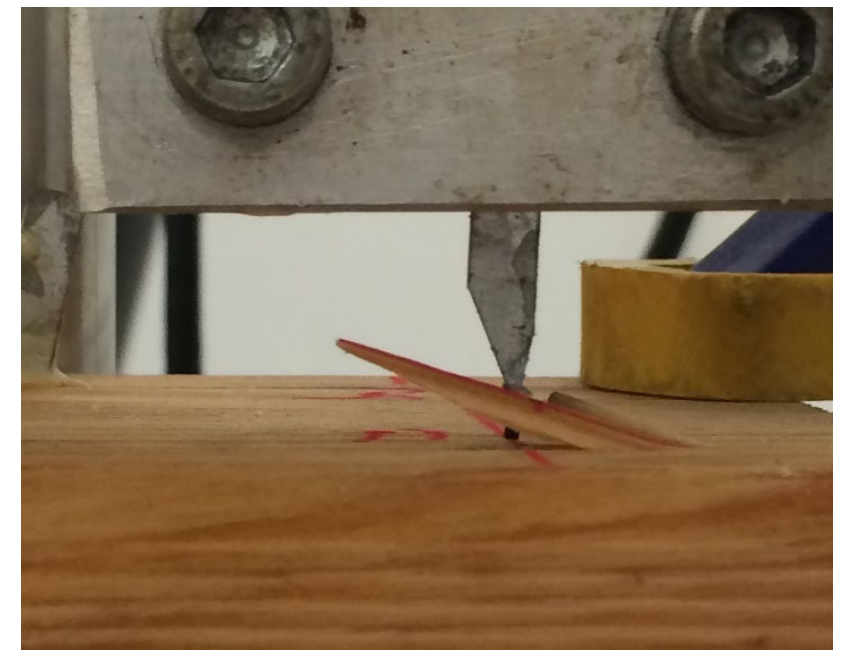

(c) MD2

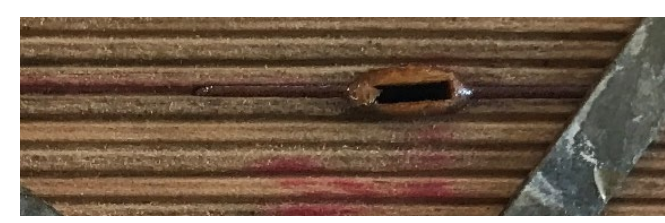

(d) Glue

Figure 14 Photos observing the withdrawal testing of the mechanical designs.

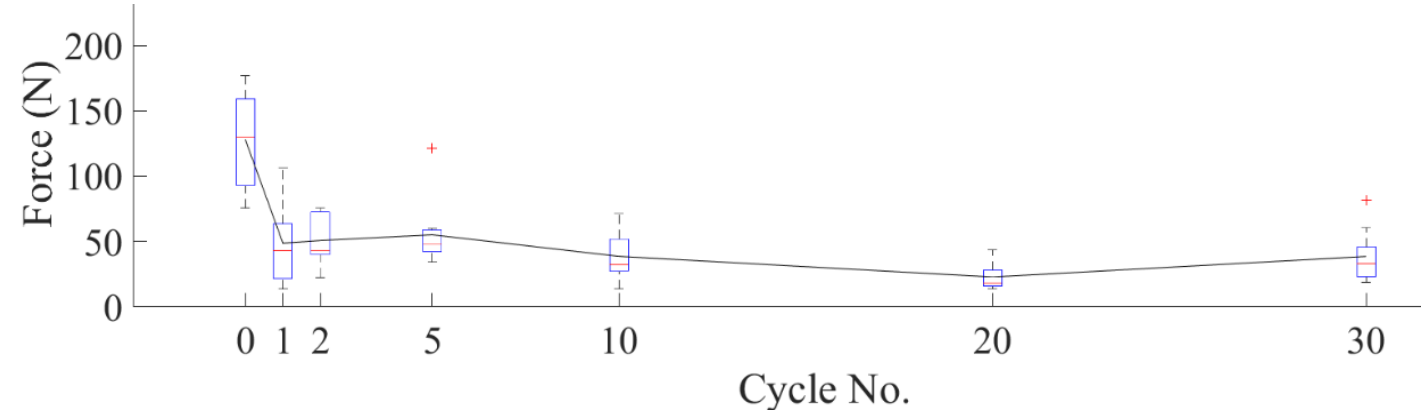

(a) Base

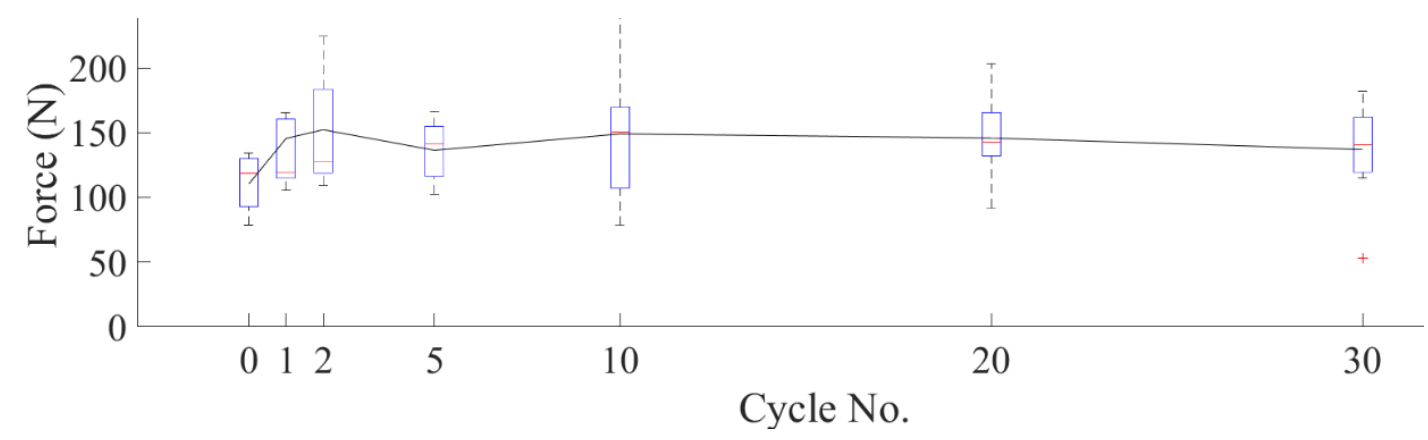

(b) MD1 


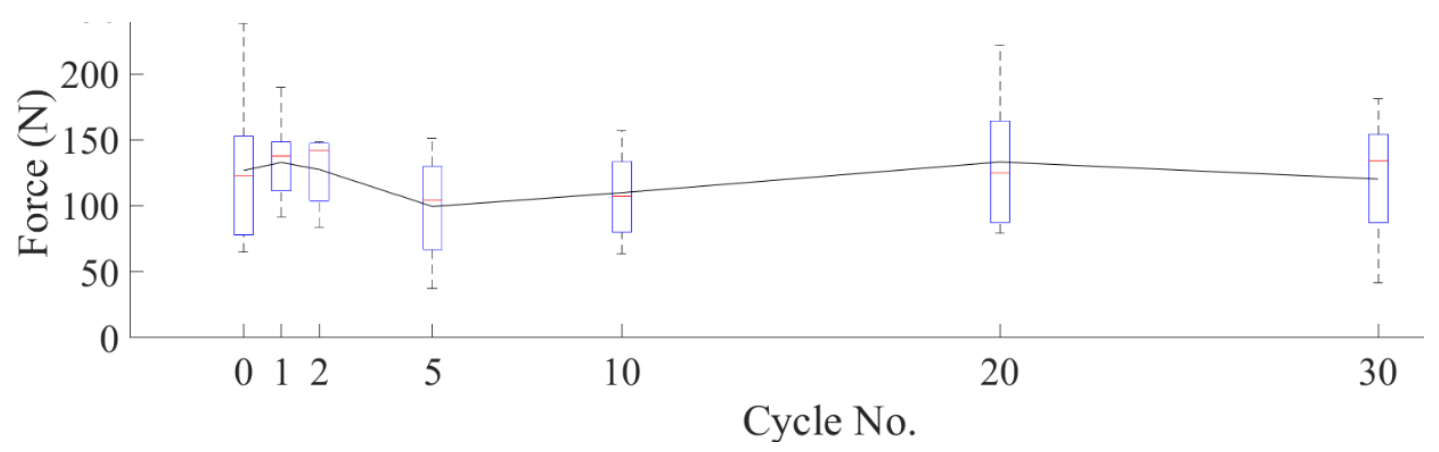

(c) MD2

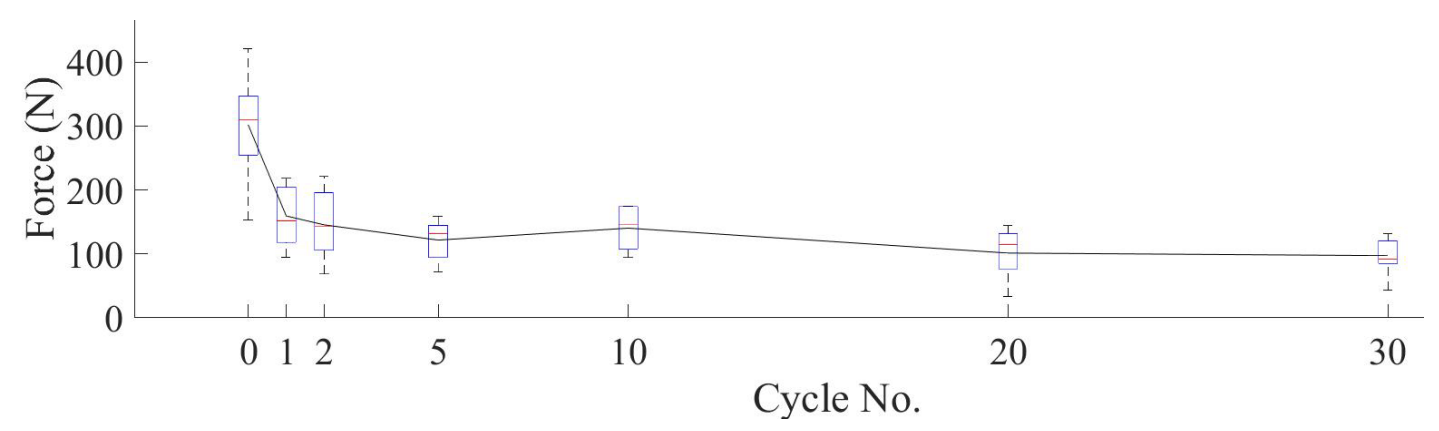

(d) Glue

Figure 15 Withdrawal force for each design using box plots

\section{Conclusions}

This paper investigated three tooth profile re-designs for nailplated joints aiming at (i) preventing moisture driven backout and (ii) increasing the withdrawal resistance of the teeth. Two mechanical based designs and one adhesive based design were investigated. When compared to reference teeth (representing teeth commercially available on the market), the mechanical based designs proved to slow the backout rate of the nail by approximately $60 \%$ after 30 accelerated MC cycles. The use of polyurethane based adhesive to the adhesive based design effectively stopped moisture driven backout. The maximum withdrawal force for each mechanical design, and the work required to remove the teeth from the timber, were only marginally affected by the number of MC cycles the timber specimen were exposed to. In 
contrast, the control (base) teeth and the adhesive based design lost up to $60 \%$ of their initial maximum withdrawal strength after one severe MC cycle. For these two designs, the maximum withdrawal force was only reduced after the first moisture cycle and remained constant for all cycle increments after that, regardless of tooth backout. The withdrawal capacity of the two mechanical and one adhesive based designs after one moisture cycle was approximately 158 $\mathrm{N}, 328 \%$ higher than the one of the control (base) teeth. The three investigated designs proved to be efficient in improving the performance of the teeth, both in term of backout and withdrawal capacity. Based on the results within this paper, the mechanical designs (both MD1 and MD2) would be a more economical and practical solutions to extend the use of timber trusses to external environments when compared to the introduction of an adhesive to the nailplate. While the results are very promising, and it has been proven that modifying the tooth profile, with and without glue, can greatly decrease the backout rate and increase the withdrawal resistance (ideally increasing the nailplate joint capacity when it fails in plate peeling), the ability of the joints to be adapted to a manufacturing environment and maintain the same level of performance for a whole joint stands to be tested. This paper leads a pathway to eventually use nailplates in weather exposed conditions and improve the structural performance and reliability of timber trusses.

\section{Acknowledgements}

The authors express their gratitude to Multinail Australia for providing the required support and material for the project. The main author also acknowledges the funding provided by the Australian Government Research Training Program Scholarship.

On behalf of all authors, the corresponding author states that there is no conflict of interest. 


\section{References}

Allday, A. (2017). "Wooden Structural Component Manufacturing in Australia." IBISWolrd IBISWorld Industry Report C1492.

Amserican National Standards Institute (1995). ANSI/TPI 1-1995 - National design standard for metal plate connected wood truss construction. New York, New York.

Atkins, W. B. (1962). Connector plate. United States of America. US3016586A.

Bylund, D. (2017). "Enabling Prefabricated Timber Building Systems for Class 2 to 9 Buildings." F. a. F. D. Australian Government Department of Agriculture Project number: PNA324-1314.

Foschi, R. O. (1977). "Analysis of wood diaphragms and trusses. Part I: Diaphragms." Canadian Journal of Civil Engineering 4(3): 345-352.

Gebremedhin, G. K. and L. P. Crovella (1991). "Load Distribution In Metal Plate Connectors Of Tension Joints In Wood Trusses." Transactions of the ASAE 34(1): 281.

Groom, L. (1995). Effect of Moisture Cycling on Mechanical Response of Metal-Plate Connector Joints With and Without an Adhesive Interface. New Orleans, Louisiana, United States Department of Agriculture - Forest Service - Research Paper so-291 - September 1995.

Groom, L. H. (1994). "Effect of moisture cycling on truss-plate joint behavior." Forest Products Journal 44(1): 21.

Houška, M. and P. Koc (2000). "Sorptive Stress Estimation: An Important Key to the Mechano-Sorptive Effect in Wood." Mechanics of Time-Dependent Materials 4(1): 81-98.

Mainey, A. J., et al. (2016). Mechanical and artificial improvement of nailplate connected timber trusses. Proceedings of the 10th World Conference on Timber Engineering WCTE2016. Vienna, Austria.

McAlister, R. H. (1990). "Tensile loading characteristics of truss plate joints after weathering and accelerated aging [1990]." Forest Products Journal 40(2): 9-15.

Melton, T. (2000). "Failures of in-service mpc parallel-chord wood floor truss components reveal deficiencies in

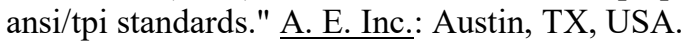

O’Neill, W. and J. T. Gabzdyl (2000). "New developments in laser-assisted oxygen cutting." Opt. Lasers Eng. 34: 355. 
Paevere, P., et al. (2008). "Nailplate Backout - is it a Problem in Plated Timber Trusses." Proceedings of the 10th World Conference on Timber Engineering WCTE2008, At Miyazaki, Japan.

Paevere, P., et al. (2009). "Mechano-Sorptive Nailplate Backout in Nailplated Timber Trusses." F. W. P. A. Limited: Australia.

Regan, P. J. and F. E. Woeste (2002). Withdrawal strength of punched metal tooth plates in red oak end grain. (Wood Engineering). Forest Products Journal. 52: 82+.

Smith, G. C., et al. (1988). Wood joint connector plate. United States of America. US4734003.

Smulski, S. (1993). "Case study: flat truss failure." Journal of Light Construction Oct: 38-39.

Standards Australia (2001). AS1649-2001 Timber - Methods of test for mechanical fasteners and connectors Basic working loads and characteristic strengths. Sydney, Australia, Standards Australia,.

Standards Australia (2006). AS/NZS 1748:2006 Timber - Mechanically stress-graded for structural purposes. Sydney, Australia, Standards Australia.

Standards Australia (2012). AS1080.1-2012 Timber - Methods of test - Moisture content. Sydney, Australia, Standards Australia \& Standards New Zealand.

Wei Guo, S. S., Zehui Jiang, Ge Wang, Zhengjun Sun, Xuehua Wang, Feng Yang, Hong Chen, Sheldon Q. Shi, Benhua Fei (2014). "Effect of Metal-Plate Connector on Tension Properties of Metal-Plate Connected Dahurian Larch Lumber Joints." Journal of Materials Science Research 3(3): 40-47. 